\title{
Studies on Structure of Cuprammonium Cellulose III. Structure of Regenerated Cellulose Treated by Cuprammonium Solution
}

\author{
Ikuya Miyamoto, Yoshio Matsuoka, Toshihiko Matsui, Masatoshi Saito, and Kunihiko Okajima \\ Fundamental Research Laboratory of Natural and Synthetic Polymers, Asahi Chemical Industry Co., Ltd., \\ 11-7 Hacchownawate, Takatsuki, Osaka 569, Japan
}

(Received September 4, 1995)

\begin{abstract}
An attempt was made to clarify the supermolecular structure of regenerated celluloses recovered from the copper-absorbing celluloses, which were prepared by treating solid cellulose with aqueous (aq) cuprammonium hydroxide $(\mathrm{CAH})$ solutions having different hydroxyl ion content $\left(C_{\mathrm{OH}}\right)$. X-Ray diffraction and CP/MAS ${ }^{13} \mathrm{C}$ NMR analyses carried out on the regenerated cellulose samples revealed that the samples had a wide variation of supermolecular structures depending on the $C_{\mathrm{OH}}$ : (1) The CAH solutions with $C_{\mathrm{OH}}<0.174 \mathrm{moll}^{-1}$ brought about the increase in crystallinity, crystalline size and intramolecular hydrogen bond formation, and (2) the CAH solutions with $C_{\mathrm{OH}}>0.479$ mol1 $1^{-1}$ tend to give the reverse results. Circular dichroism (CD) spectra for the cellulose films treated by two kinds cuprammonium solutions with $C_{\mathrm{OH}}<0.174$ and $C_{\mathrm{OH}}>0.479$ revealed that cuprammonium ions orderly coordinate to $\mathrm{C}_{2}$ and $\mathrm{C}_{3}$ hydroxyl groups of glucopyranose units of cellulose in only amorphous region in the case of $C_{\mathrm{OH}}<0.174$ and the $\mathrm{CAH}$ with $C_{\mathrm{OH}}>0.479$ penetrates into even a part of crystalline region of cellulose and causes a ligand exchange from ammonia to hydroxyl groups to give a non-dissociated complex form of cellulose having certain random cross-linking by copper atom. Thus, we concluded that the difference in the complex form of the copper-absorbing cellulose influences considerably the super-molecular structure of the regenerated celluloses.

KEY WORDS Cuprammonium Cellulose / Super-Molecular Structure / X-Ray / ${ }^{13} \mathrm{C}$ Nuclear Magnetic Resonance $\left({ }^{13} \mathrm{C}\right.$ NMR) / Circular Dichroism /
\end{abstract}

Since the Schweitzer's discovery of aq cuprammonium hydroxide $(\mathrm{CAH})$ solution as a solvent for cellulose ${ }^{1}$ as early as in 1857 the numerous efforts have been made to clarify the chemical structure of so-called cellulose/ cuprammonium complex in the solution. ${ }^{2-4}$ Typical optical rotation study on the cellulose solution made by Reeves ${ }^{5}$ predicted that an equimolar coordination of copper ion to the hydroxyl groups at $\mathrm{C}_{2}$ and $\mathrm{C}_{3}$ positions of glucopyranose unit takes place. In this connection we have recently ${ }^{6}$ found for the above solution system by ultraviolet (UV) and circular dichroism (CD) spectrophotometories that 1) copper selectively coordinates to hydroxyl groups at $\mathrm{C}_{2}$ and $\mathrm{C}_{3}$ positions of glucopyranose units in cellulose giving a $\delta$ chelate conformation and 2) intensity of CT absorption levels off when molar ratio of copper to glucopyranose unit of cellulose $(\mathrm{Cu} / \mathrm{Cell})$ in the solution exceeds $0.6-0.7$, predicting the existence of some chemical equilibrium state between cellulose, cuprammonium complex and cellulose-cuprammonium complex in the solution.

Along with these studies the crystallographical approaches to reveal the structure of copper-absorbed cellulose in solid phase have been also extensively applied. Hess and Trogus ${ }^{7}$ carried out X-ray diffraction analysis on the copper-absorbed ramie samples prepared by treating ramie with the $\mathrm{CAH}$ solution containing $\mathrm{NaOH}$. They found that when the absorbed concentration of copper is lower $(\mathrm{Cu} / \mathrm{Cell}<1)$ the copper-absorbed ramie had a fiber period of $1.05 \mathrm{~nm}$ and when the absorbed concentration of copper is higher $(\mathrm{Cu} / \mathrm{Cell}>1)$ the copper-absorbed ramie had a fiber period of $1.57 \mathrm{~nm}$. Sobue $^{8}$ also described in his monograph that in the X-ray diffraction analysis on the copper-absorbed cellulose prepared from CAH solution containing $770 \mathrm{mmoll}^{-1}$ $\mathrm{NaOH}$, the crystalline lattice characteristic to cellulose disappeared with an increase in the amount of the absorbed copper and further increase in copper content in cellulose yielded a new peak, which strongly suggests the generation of other type of crystalline system. In other words, these experimental results unquestionably indicate that the crystallographical change of cellulose solid is caused by treatment with $\mathrm{CAH}$ solutions. Unfortunately, these pioneering works had been done when crystallographical knowledge on cellulose was not yet fully accumulated and therefore their findings were not discussed in terms of crystalline form of cellulose. At present, it is well-known fact that treatment of cellulose by chemicals under appropriate conditions controls polymorphs of cellulose ${ }^{9,10}$ : for example the recovered cellulose from its any solutions shows cellulose-II type polymorph, liquid ammonia treatment gives cellulose-

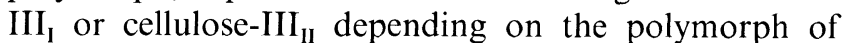
the starting cellulose. Therefore, in this sense it is also interesting to know the polymorphs of the recovered cellulose from copper-absorbed cellulose as well as super-molecular structure described later. In the previous study ${ }^{11}$ we revealed from an experiment of absorption of cuprammonium complex to cellulose solid that the equilibrium molar ratio of absorbed copper to glucopyranose unit of cellulose was 0.65 , which is almost the same value revealed for cellulose/cuprammonium solution system in the previous study. ${ }^{6}$ More important result is that two complex-forming reactions with different reaction order of $\mathrm{OH}$ ion exist depending on $\mathrm{OH}$ ion strength in the system. The reaction order of $\mathrm{OH}$ ion was determined as unity for the system with $\mathrm{OH}$ ion strength $\left(C_{\mathrm{OH}}\right)$ less than $0.3 \mathrm{moll}^{-1}$ and as zero for the system with $C_{\mathrm{OH}}>0.5 \mathrm{moll}^{-1}$, which might be related to the observation by Hess and Trougus. Although the detailed absorption equilibrium for the system with 
$0.5>C_{\mathrm{OH}}>0.3 \mathrm{moll}^{-1}$ has not been examined, more complex equilibrium is anticipated. Thus, the existence of two or more kinds of absorption equilibria depending on $C_{\mathrm{OH}}$ might lead to the different structures in the copper-absorbing cellulose solid by treating with the $\mathrm{CAH}$ solution. Therefore, it is predicted that we could have many cellulose samples with widely different supermolecular structure or polymorphs when we recover the cellulose from the copper-absorbing cellulose samples.

In this paper, an attempt was made to clear the supermolecular structures of the recovered celluloses from cuprammonium-cellulose complexes (copper-absorbed celluloses) as a function of $\mathrm{NaOH}$ or hydroxyl ion concentration of the treating media.

\section{EXPERIMENTAL}

\section{Materials}

A regenerated cellulose fiber sample was supplied from Asahi Chemical Industry Co., Ltd., and acid hydrolysis was carried using $25 \%$ aq sulfuric acid at $60^{\circ} \mathrm{C}$ for $8 \mathrm{~min}$ followed by washing with water and drying (this sample was coded as BLH-0). The characteristics of the sample BLH-0 was as followed. The degree of polymerization $(D P)=364$ as determined from eq 1 and 2 , the degree of break-down in $\mathrm{O}_{3} \cdots \mathrm{O}_{5}^{\prime}$ intramolecular hydrogen bond $\chi_{\text {am }}\left(\mathrm{C}_{3}\right)=0.65$ as determined by eq 5 and 6 , the amorphous content $\chi_{\mathrm{am}}(X)=0.40$ as determined by eq 3 and 4. All the equations are given later. The commercially available cuprammonium hydroxide (CAH) solution was supplied from Kishida Chemicals Co., Ltd., Japan, and the composition (copper $(\mathrm{Cu}) /$ ammonia $\left(\mathrm{NH}_{3}\right) /$ sucrose $\left./ \mathrm{OH}, \mathrm{moll}^{-1}\right)$ of the solution was adjusted by dilution with deionized water and addition of sodium hydroxide $(\mathrm{NaOH})$ to give $\mathrm{Cu} / \mathrm{NH}_{3} /$ Sucrose $/ \mathrm{OH}=$ $0.052 / 2.4 / 0.011 / 0.068-2.512\left(\mathrm{moll}^{-1}\right)$. The resultant solutions were employed for the further treatment of the cellulose sample. Copper content $\left(C_{\mathrm{Cu}}\right)$ and hydroxyl ion content $\left(C_{\mathrm{OH}}\right)$ in the reagents were determined according to the procedure described in the previous paper. ${ }^{11}$ Ammonia content $\left(C_{\mathrm{NH}_{3}}\right)$ and sucrose content in the reagents were calculated using the value described by supplier. Nessler's reagent containing $2.7 \mathrm{wt} \%$ mercurous iodide supplied from Wako Chemicals (Japan) was used for determination of $\mathrm{NH}_{3}$ in solution.

\section{Sample Treatment and Analytical Procedure}

1.53 gram ( $w_{0} \mathrm{~g}$, dry base) of the regenerated cellulose (BLH-0) was immersed in $142.8 \mathrm{~g}$ of the $\mathrm{CAH}$ solutions with different $C_{\mathrm{OH}}\left(\mathrm{Cu} / \mathrm{NH}_{3} /\right.$ sucrose $/ \mathrm{OH}=0.052 / 2.4$ / $\left.0.011 / 0.068-2.512 \mathrm{moll}^{-1}\right)$ stocked in an Erlenmeyer flask with silicon rubber stopper at $25^{\circ} \mathrm{C}$ for $1 \mathrm{~h}$ in a dark place and the undissolved crude blue cellulose solid (hereafter denoted as CBC) was separated from the mixture on the glass filter, washed with $c a .20 \mathrm{ml}$ of methanol and dried at $50^{\circ} \mathrm{C}$ for $2 \mathrm{~h}$ obtaining the dried blue cellulose sample(hereafter denoted as DBC) and then weighed $\left(w_{\mathrm{BC}} \mathrm{g}\right)$. These are coded as DBC-1-DBC12. DBC samples were subsequently subjected to the regeneration process where DBC samples were regenerated with $1 \mathrm{~N}$ aq $\mathrm{HCl}$ at $25^{\circ} \mathrm{C}$ for $2 \mathrm{~h}$, washed by water, dried in air and finally dried at $90^{\circ} \mathrm{C}$ for $2 \mathrm{~h}$ and then weighed $\left(w_{\mathrm{ns}} \mathrm{g}\right)$. Twelve cellulose samples thus Polym. J., Vol. 28, No. 3, 1996 prepared were recovered and coded as BLH-1-BLH-12 and were subjected to $\mathrm{CP} / \mathrm{MAS}{ }^{13} \mathrm{C} \mathrm{NMR}$ and $\mathrm{X}$-ray analyses. The resultant washing liquids obtained from the regeneration process (Soln C) were subjected to $\mathrm{Cu}$ analysis to estimate $\mathrm{Cu}$ content absorbed by the cellulose.

\section{Analyses}

The viscosity-average degree of polymerization $D P$ of cellulose: $D P$ of the original celluloses $(\mathrm{BLH}-0)$ and the recovered celluloses (BLH-1-12) was determined from the limiting viscosity number $[\eta]$ in cadoxen at $25^{\circ} \mathrm{C}$ using the following equation ${ }^{12}$ :

$$
\begin{gathered}
{[\eta]=3.85 \times 10^{-4} M_{w}^{0.76}} \\
D P=M_{w} / 162
\end{gathered}
$$

X-Ray diffractometry X-ray diffraction patterns of the original and recovered cellulose samples were recorded on a X-ray diffractometer (Roter Flex RU-300, Rigaku Denki Co., Ltd., Japan) by reflection method. The crystallinity $\chi_{\mathrm{c}}(X)$ was estimated by Segal's method, ${ }^{13}$ using the relations:

$$
\chi_{\mathrm{c}}(X)=\left(I_{(002)}-I_{\mathrm{am}}\right) / I_{(002)}
$$

And amorphous content $\chi_{\text {am }}(X)$ was defined as

$$
\chi_{\mathrm{am}}(X)=1-\chi_{\mathrm{c}}(X)
$$

Here, $I_{(002)}$ and $I_{\mathrm{am}}$ mean the peak intensities corresponding to $(002)$ plane $\left(2 \theta=21.9^{\circ}\right)$ and amorphous $\left(2 \theta=16.0^{\circ}\right)$. Half value widths for the peaks $(2 \theta=20.0$ and $21.9^{\circ}$ ) responsible for (101) and (002) plane, $\Delta 1 / 2(10 \overline{1}), \Delta 1 / 2(002)$ were also estimated as follows: A base line was drawn between $2 \theta=14^{\circ}$ and $28^{\circ}$ and on this base line a line from the corresponding peak position $\left(\mathrm{P}_{10 \overline{1}}\right.$ or $\left.\mathrm{P}_{002}\right)$ was drawn in parallel to intensity axis and the crossing point $\left(\mathrm{O}_{10 \overline{1}}\right.$ or $\left.\mathrm{O}_{002}\right)$ was determined. Middle points $\mathrm{Q}_{10 \overline{1}}$ and $\mathrm{Q}_{002}$ for lines $\mathrm{O}_{10 \overline{1}} \mathrm{P}_{10 \overline{1}}$ and $\mathrm{O}_{002} \mathrm{P}_{002}$, respectively, were set up. From each middle point a line parallel to the base line was drawn so as to cross the diffraction pattern $\left(\mathrm{Q}_{101}^{\prime}\right.$ or $\left.\mathrm{Q}_{002}^{\prime}\right)$ and the distances between $\mathrm{Q}_{101} \mathrm{Q}_{10 \overline{1}}^{\prime}$ and $\mathrm{Q}_{002} \mathrm{Q}_{002}^{\prime}$ were regarded as $\Delta 1 / 2(10 \overline{1})$ and $\Delta 1 / 2(002)$.

\section{${ }^{13}$ C NMR Measurement}

$\mathrm{CP} / \mathrm{MAS}{ }^{13} \mathrm{C}-\mathrm{NMR}$ spectra for the original and recovered cellulose solids were recorded on a FT-NMR spectrometer (FX200 JEOL, Japan) at room temperature under the following operating conditions: $90^{\circ}$ pulse width; $5.5 \mu \mathrm{s}$, cross polarization contact time; $2 \mathrm{~ms}$, pulse repetition; $5 \mathrm{~s}$, spinning rate; $2.5-3.5 \mathrm{kHz}$, data points; 8192 (4096 zero-filling), accumulation; 200-1024, spectral width; $20,000 \mathrm{~Hz}$, acquisition time; $102.4 \mathrm{~ms}$. Chemical shifts for $\mathrm{C}_{1}, \mathrm{C}_{4}$, and $\mathrm{C}_{6}$ carbon peaks and their half value width were analyzed. Apparent degree of break-down in intramolecular hydrogen bond at $\mathrm{O}_{3} \mathrm{H}-\mathrm{O}_{5}^{\prime}$ of the samples $\chi_{\mathrm{am}}\left(\mathrm{C}_{3}\right)$ was also determined according to the method proposed for cellulose solid having crystal form of cellulose-II ${ }^{14}$ using the following equation:

$$
\begin{aligned}
\chi_{\mathrm{am}}\left(\mathrm{C}_{3}\right) & =I h\left(\mathrm{C}_{4}\right) /\left\{I h\left(\mathrm{C}_{4}\right)+I l\left(\mathrm{C}_{4}\right)\right\} \\
& =1-I l\left(\mathrm{C}_{4}\right) / I \mathrm{C}_{1}
\end{aligned}
$$


Here, $I h\left(\mathrm{C}_{4}\right)$ and $I l\left(\mathrm{C}_{4}\right)$ are the fractions of higher and lower magnetic field peaks in the $\mathrm{C}_{4}$ carbon peak region $(80-89 \mathrm{ppm}) . I \mathrm{C}_{1}$ is the total peak intensity for $\mathrm{C}_{1}$ carbon peak area.

\section{Copper Content}

Copper content in Soln C (that is, copper absorbed by cellulose, $W_{\mathrm{Cu}(\mathrm{a})}$ ) was determined gravimetrically by converting cupric ion into cupric sulfide $(\mathrm{CuS})$ in the following manner; $2.0 \mathrm{~g}$ of sodium sulfide with 9 hydrates $\left(\mathrm{Na}_{2} \mathrm{~S} \cdot 9 \mathrm{H}_{2} \mathrm{O}\right)$ was added in soln $\mathrm{C}$, and stood at room temperature for $8 \mathrm{~h}$ to allow production of black precipitate of $\mathrm{CuS}$ to proceed completely. The $\mathrm{CuS}$ was separated on a glass filter, whose weight $\left(W_{\mathrm{g}}\right)$ was measured in advance after drying at $105^{\circ} \mathrm{C}$ for $3 \mathrm{~h}$, and the total weight of the $\mathrm{CuS}$ with the glass filter $\left(W_{\mathrm{gc}}\right)$ was measured after drying at $105^{\circ} \mathrm{C}$ for $3 \mathrm{~h} . W_{\mathrm{Cu}(\mathrm{a})}$ was determined through eq 7 .

$$
W_{\mathrm{Cu}(\mathrm{a})}=\left(W_{\mathrm{gc}}-W_{\mathrm{g}}\right) \times 63.55 / 95.61
$$

Molar absorption of $\mathrm{Cu}$ on the undissolved cellulose at equilibrium $\left(M_{\mathrm{Cu}} / M_{\mathrm{Cel1}}\right)$ is defined as;

$$
M_{\mathrm{Cu}} / M_{\mathrm{Cell}}=\left(W_{\mathrm{Cu}(\mathbf{a})} / 63.55\right) /\left(w_{\mathrm{ns}} / 162\right)
$$

Hydroxyl Ion Content of the Cuprammonium Solution

Before measurement the $\mathrm{pH}$ meter (glass electrode, HM-18E type, Toa Denpa Co., Japan) was calibrated at $20^{\circ} \mathrm{C}$ to indicate precisely $\mathrm{pH}=13.1$ by using $0.10 \mathrm{~N}$ aq $\mathrm{NaOH}$ standard solution. The $\mathrm{pH}$ of the system was measured by the $\mathrm{pH}$ meter at $20^{\circ} \mathrm{C}$. The measured $\mathrm{pH}$ value was translated to $\mathrm{OH}$ ion concentration using the following equation:

$$
\left[\mathrm{OH}^{-}\right]=10^{(\mathrm{pH}-14)}
$$

\section{Circular Dichroism (CD) Measurement}

The spectra of a transparent regenerated cellulose film $(D P=300)$ treated by $\mathrm{CAH}$ solutions with two $\mathrm{OH}$ concentrations $\left(C_{\mathrm{OH}}=0.068\right.$ and $\left.0.575 \mathrm{moll}^{-1}\right)$ and the given $\mathrm{Cu}$-absorbed cellulose films were recorded on a CD spectrophotometer (J-720, JASCO, Japan). Operating conditions are follows: band width, $1.0 \mathrm{~nm}$; sensitivity, $1000 \mathrm{mdeg}$; response, $0.5 \mathrm{~s}$; wavelength range, $200-800 \mathrm{~nm}$; step resolution, $1 \mathrm{~nm} /$ data; accumulation, 1.

\section{RESULTS AND DISCUSSION}

Table I collects the hydroxyl ion concentration $C_{\mathrm{OH}}$ of the CAH solutions employed for preparation of $\mathrm{DBC}$ samples, the solubility $S_{\mathrm{co}}\left(=100 \times\left(w_{\mathrm{o}}-w_{\mathrm{ns}}\right) / w_{\mathrm{o}}(\%)\right)$ of cellulose (BLH-0) determined in the preparing process of DBC samples, and their molar absorption of copper $\left(M_{\mathrm{Cu}} / M_{\mathrm{Cel1}}\right)$. As previously reported, ${ }^{11} S_{\text {co }}$ increased with an increase in $C_{\mathrm{OH}}$ approaching a maximum around $C_{\mathrm{OH}}=0.339$, then rapidly decreased to $S_{\mathrm{co}}=c a .0$ at $C_{\mathrm{OH}} \geqq$ 0.575 , and $M_{\mathrm{Cu}} / M_{\mathrm{Cell}}$ also increased with an increase in $C_{\mathrm{OH}}$ approaching an asymptotic value $\left(M_{\mathrm{Cu}} / M_{\mathrm{Cell}}\right.$ value $=c a .0 .52)$ at $C_{\mathrm{OH}}>0.479 . \mathrm{DBC}$ samples obtained by treating with $\mathrm{CAH}$ solutions with $C_{\mathrm{OH}}>0.479$ (DBC-8-12) were almost same in the $M_{\mathrm{Cu}} / M_{\mathrm{Cell}}$ value $(=c a .0 .52)$ and another DBC samples were lower in $M_{\mathrm{Cu}} / M_{\text {Cell }}$ value.

Figure 1 shows the X-ray diffraction patterns of the original and the recovered celluloses (BLH samples) obtained by disrobing copper from the DBC samples.

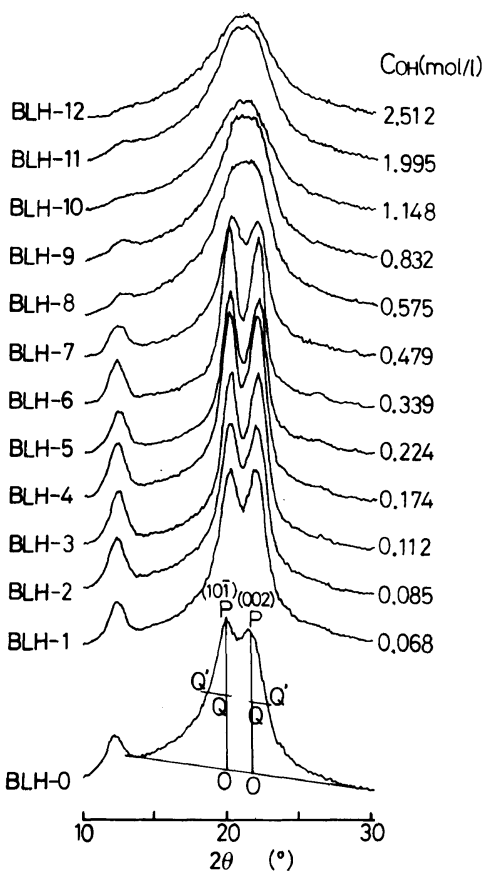

Figure 1. X-Ray diffraction patterns of the original and recovered cellulose samples.

Table I. Preparation condition of DBC samples, their molar absorptions for copper, and structural parameters of the recovered celluloses from DBC samples and degree of polymerization $(D P)$

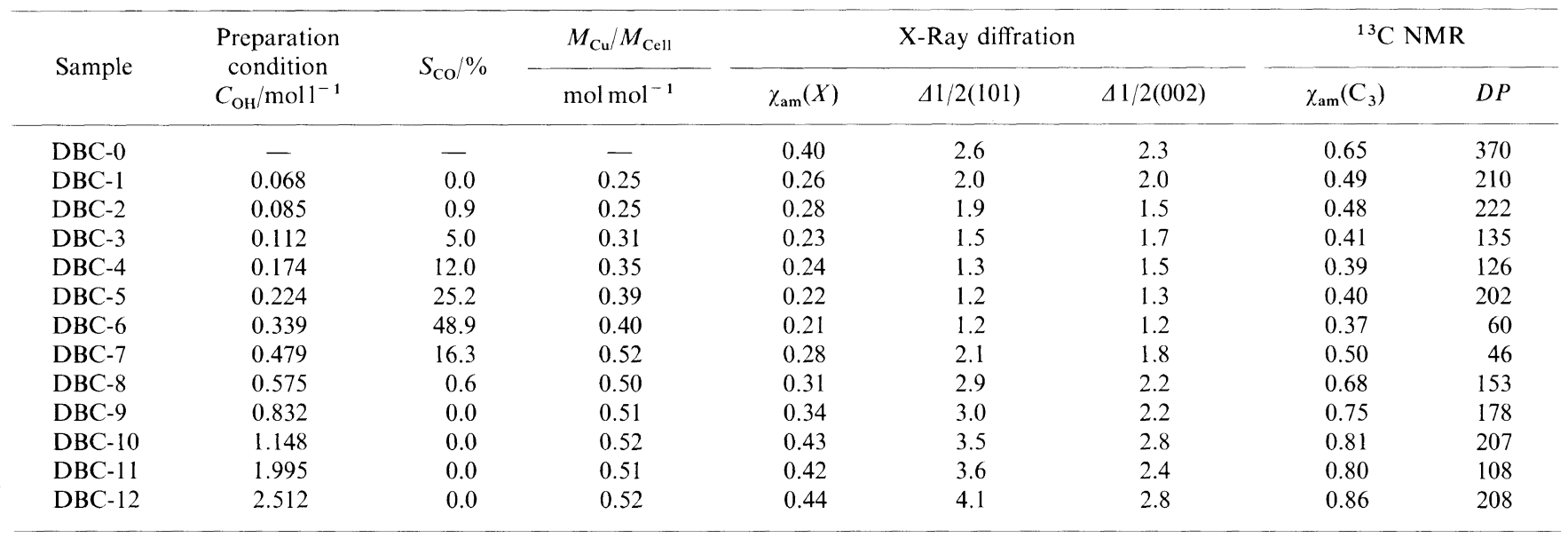




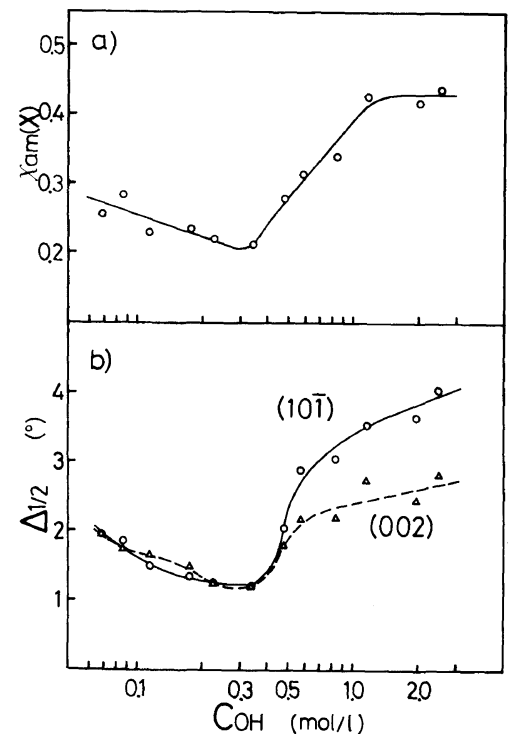

Figure 2. Relation between the structural parameters of the recovered cellulose determined by X-ray analysis. (a, $\chi_{\mathrm{am}}(X) ; \mathrm{b}, \Delta 1 / 2(10 \overline{1})$ and $\Delta 1 / 2(002))$ and the hydroxyl ion concentration $\left(C_{\mathrm{OH}}\right)$ of cuprammonium solutions employed for preparation of the recovered cellulose.

Original regenerated sample (BLH-0) shows two peaks at $2 \theta=20.0^{\circ}$ corresponding to $(10 \overline{1})$ plane and $21.9^{\circ}$ corresponding to (002) plane characteristic to cellulose-II crystal and the characteristic feature maintained for the recovered cellulose samples prepared by treating with $\mathrm{CAH}$ solutions having $C_{\mathrm{OH}} \leqq 0.479$. For the recovered samples obtained by treating with $\mathrm{CAH}$ solutions having $C_{\mathrm{OH}} \geqq 0.575$ the above two peaks seem to merge into one broad envelope. The separation of two peaks became better for the recovered samples in the range of $C_{\mathrm{OH}} \leqq$ 0.339 . The amorphous content $\left(\chi_{\mathrm{am}}(X)\right)$, the half value width of the peaks $(\Delta 1 / 2(10 \overline{1}), \Delta 1 / 2(002))$ are summarized in the fifth-seventh columns of Table I. Table I also collects the degree of polymerization $(D P) . D P$ of the recovered samples lies 108 to 222 except BLH-6 and BLH-7.

Figure 2 shows the relation between the structural parameters $\left(\chi_{\mathrm{am}}(X), \mathrm{a}\right), \Delta 1 / 2(10 \overline{1})$ and $\left.\Delta 1 / 2(002), \mathrm{b}\right)$ of the recovered cellulose samples determined by X-ray analysis and the hydroxyl ion concentration $C_{\mathrm{OH}}$ of the $\mathrm{CAH}$ solutions employed. Here, the region $0.174 \leqq$ $C_{\mathrm{OH}} \leqq 0.479$ corresponds to the cellulose dissolving region more or less when treated with those solution, then a strict discussion is not possible. Therefore, our discussion will be limited to the regions of $0.174>C_{\mathrm{OH}}$ and $C_{\mathrm{OH}}>0.479$. In the region of $C_{\mathrm{OH}}<0.174$ the $\chi_{\mathrm{am}}(X)$ gradually decreases with an increase in $C_{\mathrm{OH}}$ and beyond the dissolving region $\chi_{\mathrm{am}}(X)$ increases drastically in the region of $C_{\mathrm{OH}}>0.575$, leading to an asymptotic value. $\Delta 1 / 2(10 \overline{1})$ and $\Delta 1 / 2(002)$ also change their tendency before and beyond the dissolving region, getting smaller and larger with $C_{\mathrm{OH}}$ before and beyond the dissolving region, respectively.

Figure 3 shows $\mathrm{CP} / \mathrm{MAS}{ }^{13} \mathrm{C}$ NMR spectra of the recovered cellulose samples shown in Table II. Peak assignment is given on the figure. A shoulder peak ( $c a$. $104 \mathrm{ppm}$ ) appeared on the main $\mathrm{C}_{1}$ carbon peak ( $c a$. $103 \mathrm{ppm}$ ) for the original sample became distinct in the $C_{\mathrm{OH}}$ region of $0.068-0.479$ showing the increase in

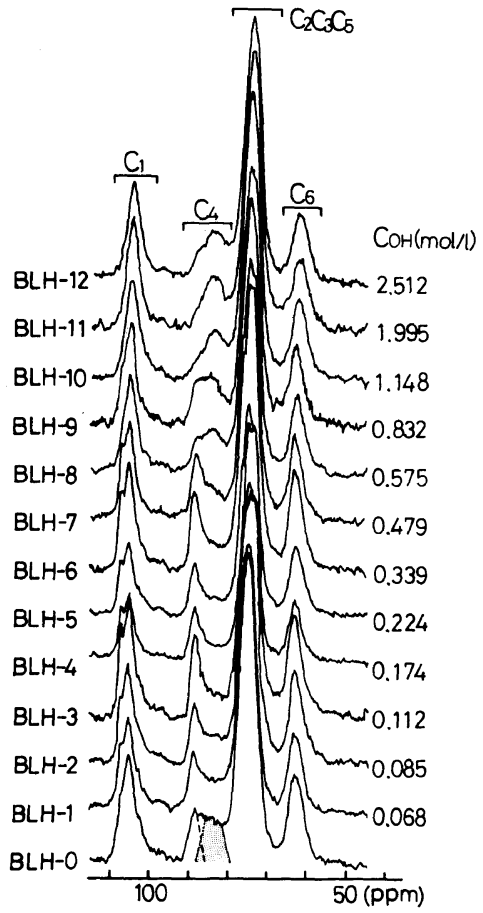

Figure 3. $\mathrm{CP} / \mathrm{MAS}{ }^{13} \mathrm{C} \mathrm{NMR}$ spectra of the original and recovered cellulose samples.

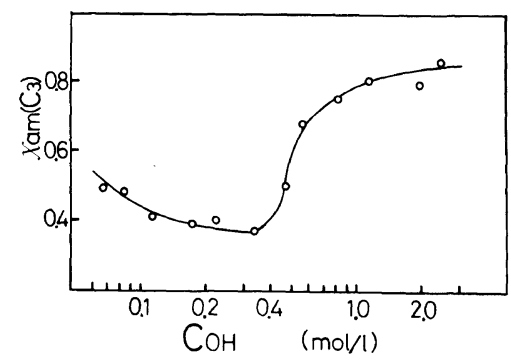

Figure 4. Dependence of $\chi_{\mathrm{am}}\left(\mathrm{C}_{3}\right)$ of the recovered cellulose determined by $\mathrm{CP} / \mathrm{MAS}{ }^{13} \mathrm{C}$ NMR analysis on the hydroxyl ion concentration $\left(C_{\mathrm{OH}}\right)$ of cuprammonium solutions employed for preparation of the recovered cellulose.

regularity of molecular packing of the recovered sample. In the same $C_{\mathrm{OH}}$ region the fraction of the sharp peak (ca. $89 \mathrm{ppm}$ ) in $\mathrm{C}_{4}$ carbon region is larger than that for the original. The sharp peak abruptly decreased at $C_{\mathrm{OH}} \geqq$ 0.575 . The envelope including $\mathrm{C}_{2}, \mathrm{C}_{3}$, and $\mathrm{C}_{5}$ carbon peaks slightly changes depending on $C_{\mathrm{OH}}$ of the $\mathrm{CAH}$ solutions employed. Broadness of $\mathrm{C}_{6}$ carbon peak $(61.5 \mathrm{ppm})$ also proved to be considerably dependent on $C_{\mathrm{OH}}$. The degree of break-down in $\mathrm{O}_{3} \mathrm{H}_{\cdots} \mathrm{O}_{5}^{\prime}$ intramolecular hydrogen bond $\left(\chi_{\mathrm{am}}\left(\mathrm{C}_{3}\right)\right)$ is listed in 8th columns of Table I.

Figure 4 shows the relationship between $\chi_{\mathrm{am}}\left(\mathrm{C}_{3}\right)$ of the recovered cellulose samples determined by $\mathrm{CP} / \mathrm{MAS}$ ${ }^{13} \mathrm{C}$ NMR analysis ${ }^{5}$ and the hydroxyl ion concentration $C_{\mathrm{OH}}$ of the $\mathrm{CAH}$ solutions employed. $\chi_{\mathrm{am}}\left(\mathrm{C}_{3}\right)$ gave quite similar dependence on $C_{\mathrm{OH}}$ as observed for $\Delta 1 / 2(10 \overline{1})$ $C_{\mathrm{OH}}$ relation and $\chi_{\mathrm{am}}(X)-C_{\mathrm{OH}}$ shown in Figure 2.

In the previous study we pointed out ${ }^{11}$ that cuprammonium complex in cuprammonium solution with $C_{\mathrm{OH}}<0.3 \mathrm{~mol}$ is ionized and its counter ion (hydroxyl ion) participates in a kind of absorption equilibrium between cellulose and cuprammonium complex with reaction order of unity. On the other hand, when $C_{\mathrm{OH}}$ 
in the cuprammonium solution is more than $0.5 \mathrm{moll}^{-1}$ the cuprammonium complex is not dissociated and no participation to the above equilibrium despite of the abundant free $\mathrm{OH}$ ion in the system.

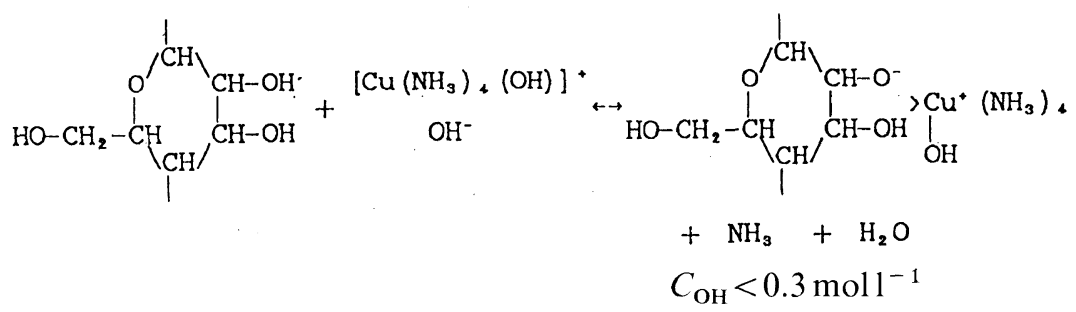

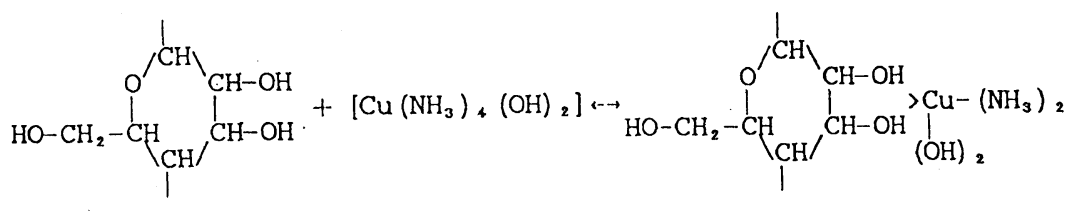

$+2 \mathrm{NH}_{3}$

$C_{\mathrm{OH}}>0.5 \mathrm{moll}^{-1}$

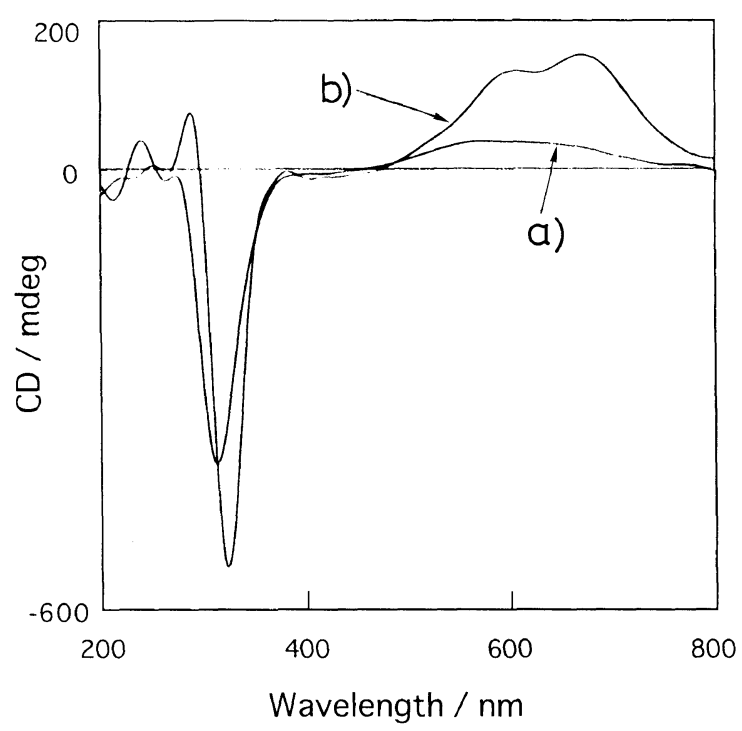

Figure 5. Circular dichroism (CD) spectra of the Cu-absorbing cellulose films treated by cuprammonium solution with different hydroxyl ion concentration $\left(C_{\mathrm{OH}}\right)$. a, $C_{\mathrm{OH}}=0.068 ; \mathrm{b}, C_{\mathrm{OH}}=0.575$.

The $C_{\mathrm{OH}}$ regions giving different complex forms are comparatively similar to those appeared in view of super-molecular structure of the regenerated celluloses in the present study, indicating that the cellulose/cuprammonium complex form might determine the structure of the regenerated cellulose.

Figure 5 shows $\mathrm{CD}$ spectra of the $\mathrm{Cu}$-absorbed cellulose films treated by the $\mathrm{CAH}$ solutions with $C_{\mathrm{OH}}=$ 0.068 and $0.575 \mathrm{moll}^{-1}$, which are representative for $\mathrm{CAH}$ soln bringing about the cellulose with high and low crystallinity, respectively after the treatment followed by regeneration. The film treated with the $\mathrm{CAH}$ with $C_{\mathrm{OH}}=0.068$ exhibits a negative CD peak around $300 \mathrm{~nm}$ responsible for CT excitation of cellulose-copper chelate and two positive and very broad CD peaks with weak intensity around 550 and $650 \mathrm{~nm}$ due to $\mathrm{d}-\mathrm{d}$ excitation of cupric ion. These three CD peaks are found at almost similar positions and originated from the chelate coordination of cuprammonium ion to the two hydroxyl groups at $\mathrm{C}_{2}$ and $\mathrm{C}_{3}$ positions of glucopyranose unit of cellulose dissolved in the solution, as previously shown. ${ }^{6}$

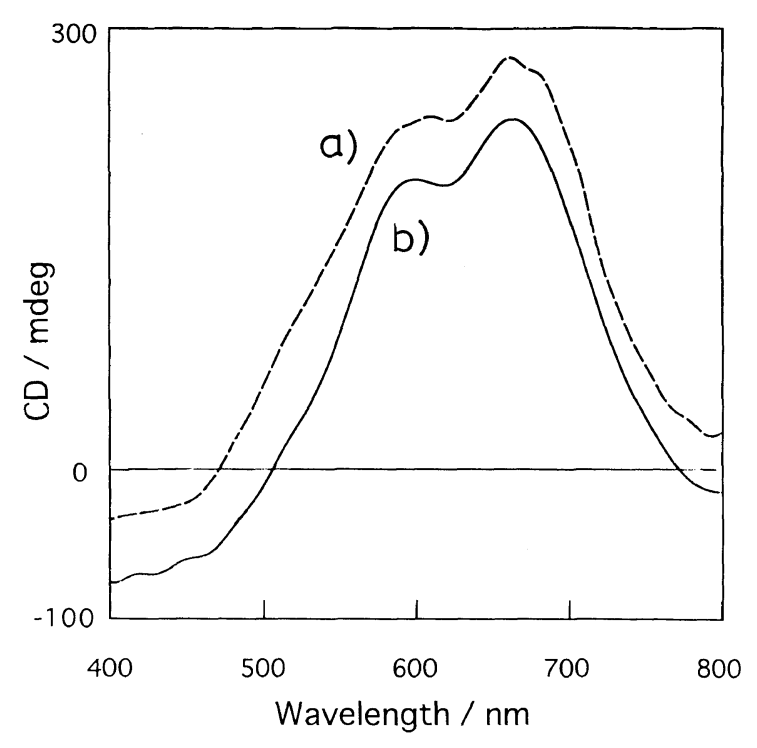

Figure 6. Circular dichroism (CD) spectrum of cuprammoniumcellulose gel obtained by coagulation of cellulose cuprammonium solution by aq $\mathrm{NaOH}$ (a) and $\mathrm{Cu}$-absorbed cellulose film treated by cuprammonium solution with $C_{\mathrm{OH}}=0.575$ (b).

This means that the present solid-liquid absorption process also gives a regio-selective coordination of copper to the two hydroxyl groups at $\mathrm{C}_{2}$ and $\mathrm{C}_{3}$ positions of cellulose. On the other hand, the film treated with the $\mathrm{CAH}$ with $C_{\mathrm{OH}}=0.575$ also gives a negative $\mathrm{CD}$ peak around $300 \mathrm{~nm}$ but gives two positive and strong peaks around 570 and $680 \mathrm{~nm}$. The strong intensity at $570 \mathrm{~nm}$ for the latter film might be attributable to the large amount of up-take of copper, as shown in Table I. The $\mathrm{d}-\mathrm{d}$ excitation of cupric ion in the wavelength range of $570-800 \mathrm{~nm}$ has been known to split by the change in species of ligand or the change in coordination form. ${ }^{15}$ In the present case, the exchange of ammonia with $\mathrm{OH}$ ion might be possible by forming non-dissociation type complex, as pointed out previously. ${ }^{11}$

Figure 6 illustrates the CD spectrum corresponding to the $d-d$ excitation, of the cuprammonium cellulose gel (so-called Norman compound) obtained from the cellulose/cuprammonium solution by treating it with aq $\mathrm{NaOH}$ solution with high concentration. In the figure, 
a)

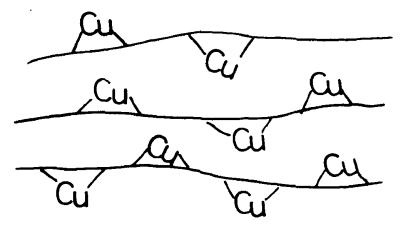

b)

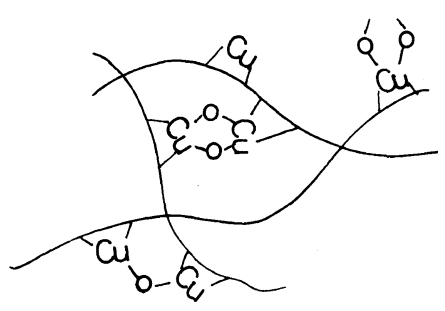

Figure 7. Schematic representation of the structures of $\mathrm{Cu}$-absorbing celluloses obtained by treating cellulose with aq. cuprammonium hydroxide solution having $C_{\mathrm{OH}}<0.174$ (a) and $C_{\mathrm{OH}}>0.479$ (b).

the CD spectrum of the film treated by the CAH with $C_{\mathrm{OH}}=0.575$ is shown for comparison. In the gel cellulose network structure is inferred to be formed by the ligand exchange of the cupric ion from ammonia molecules into hydroxyl groups, resulting in the cupric chelate complex as crosslinking reagent of cellulose molecules. ${ }^{16}$ For trivalence ferric $\left(\mathrm{Fe}^{\mathrm{III}}\right)$ and other metallic ion aqueous solutions added by sodium hydroxide, it is reported ${ }^{17}$ that the ligand exchange from water molecules to hydroxide ions occurs and produces the poly-nuclear complex which precipitate from the solution in the form of so-called polymeric hydroxide compounds. In this figure, it should be noted that the spectrum of the film treated by the $\mathrm{CAH}$ with $C_{\mathrm{OH}}=0.575$ is quite similar to that for Norman compound. So, the structure of the film treated by the $\mathrm{CAH}$ with $C_{\mathrm{OH}}=0.575$ could be characterized by the ligand-exchanging from ammonia to $\mathrm{OH}$ and a cross-linking of the cellulose molecules by poly-nuclear cupric chelate. Tentative structures for the above two $\mathrm{Cu}$-absorbed cellulose films are illustrate in Figure 7 . In the case of $C_{\mathrm{OH}}<0.174$, cupric ions selectively form a chelate-coordination to hydroxyl groups at $\mathrm{C}_{2}$ and $\mathrm{C}_{3}$. Since cupric ions (or cuprammonium ions) might preferentially penetrate only into amorphous parts of cellulose and its absolute penetrating amounts is estimated to be $M_{\mathrm{Cu}} / M_{\mathrm{Cell}}=0.25$ from Table I. The selective and ordered coordination of cuprammonium ions to amorphous part of cellulose might regularly rearrange the molecular chain of cellulose around the crystallites part, leading to an increase in crystalline size and crystallinity, and degree of intramolecular hydrogen bond of $\mathrm{O}_{3} \mathrm{H}-\mathrm{O}_{5}^{\prime}$. On the other hand, the $\mathrm{CAH}$ solution with $C_{\mathrm{OH}}>0.479$ gives some random cross-linking complex form by copper and the absolute amount of absorbed copper is considerably high $\left(M_{\mathrm{Cu}} / M_{\mathrm{Cell}}=0.5\right)$. These facts mean that a part of copper in some forms may penetrate into even crystalline region especially into the space of $(10 \overline{1})$ plane, degrading some crystalline regions, as seen in Figure 5. The relatively small $\chi_{\mathrm{am}}\left(\mathrm{C}_{3}\right)$ of the regenerated cellulose from $\mathrm{CAH}$ solutions with $C_{\mathrm{OH}}>0.479$ is plausibly explained by the selective coordination of cupric ions to hydroxyl groups at $\mathrm{C}_{2}$ and $\mathrm{C}_{3}$ positions.

\section{CONCLUSIONS}

An attempt was made to clarify the change of supermolecular structure of regenerated cellulose recovered from the copper-absorbing cellulose which were obtained by treating with cuprammonium hydroxide solution systems. For this purpose we prepared the various copper-absorbing cellulose samples (DBC) by using the cuprammonium solutions with various hydroxyl ion concentration and obtained the various recovered cellulose samples (BLH) by washing DBC samples with acidic water. X-Ray diffraction and $\mathrm{CP} / \mathrm{MAS}{ }^{13} \mathrm{C} \mathrm{NMR}$ analyses carried out on BLH samples revealed that these samples had a wide variation of supermolecular structures depending on the $C_{\mathrm{OH}}$ in the cuprammonium solutions used for the treatment.: (1) The cuprammonium solutions with $C_{\mathrm{OH}}<0.174 \mathrm{moll}^{-1}$ brought about the increase in homogeneity of structure (crystallinity and formation of intramolecular hydrogen bond) of the cellulose, and (2) the cuprammonium solutions with $C_{\mathrm{OH}}>0.479 \mathrm{moll}^{-1}$ tend to give the reverse results (lowering in the homogeneity of structures). These results could be well correlated to the complex forms of the copper-absorbing cellulose as proved by $\mathrm{CD}$ and elemental analyses: 1) Cuprammonium ion is orderly coordinated to $\mathrm{C}_{2}$ and $\mathrm{C}_{3}$ hydroxyl groups of glucopyranose units of cellulose in the case of $C_{\mathrm{OH}}<0.174$ and the penetration of copper takes place only in amorphous part, rearranging the molecular chain of cellulose somewhat regularly, 2) in the case of $C_{\mathrm{OH}}>0.479$, copper penetrate even into crystalline region of cellulose and ammonia as a ligand for cellulose exchanges with hydroxyl ion leading to an non-dissociated complex form of cellulose having certain random cross-linking by copper atom, degrading some regularity of the molecular chain. Thus, we concluded that the difference in the complex form of the copper-absorbing cellulose influences considerably the super-molecular structure of the regenerated celluloses.

\section{REFERENCES}

1. E. Schweitzer, J. Prakt. Chem., 72, 109 (1857).

2. W. Traube, Ber., 54, 3320 (1920).

3. S. M. Neale, J. Textile Inst., 16, T363 (1925).

4. T. Lieser and R. Ebert, Ann. Chem., 528, 281; ibid., 532, 89 (1937).

5. R. E. Reeves, Science, 99, 148 (1944); ibid., 94 (1937).

6. I. Miyamoto, M. Inamoto, T. Matsui, M. Saito, and K. Okajima, to be submitted.

7. C. Trogus and K. Hess, Z. Phys. Chem., B6, 1 (1929).

8. H. Sobue, Jinzosenigaku, 120 (1950)

9. K. Hess, C. Trogus, Z. Phys. Chem., B11, 381 (1931).

10. A. Barry, F. Peterson, and J. King, J. Am. Chem. Soc., 58, 333 (1936).

11. I. Miyamoto, Y. Matsuoka, T. Matsui, and K. Okajima, to be submitted.

12. W. Brown and R. Wikström, Eur. Polym. J., 1, 1 (1966).

13. L. Segal, Text. Res. J., 29, 786 (1959).

14. K. Kamide, K. Okajima, T. Matsui, and K. Kowsaka, Polym. J., 16, 857 (1984).

15. S. Yamada, "Haiikagoubutu no Kouzou," Kagakudoujin Ltd., Kyoto, 1983, chapter 10, pp 339 and 345.

16. T. Nakayama, Mem. Fac. Educ. Niigata Univ., 30 (2), 81 (1989).

17. K. Saito, "Atarashii Sakutai no Kagaku," Nippon Kagakukai, Ed., Dainippontosho Publishing Co., Tokyo, 1986, Chapter 4, p 115. 